\title{
Factors Influencing Pesticide Use in Smallholder Rice Production in Northern Ghana
}

\author{
Benjamin Tetteh Anang ${ }^{1,}$, Joseph Amikuzuno ${ }^{2}$ \\ ${ }^{1}$ Department of Agricultural and Resource Economics, FACS, University for Development Studies, Tamale, Ghana \\ ${ }^{2}$ Department of Climate Change and Food Security, FACS, University for Development Studies, Tamale, Ghana
}

\section{Email address:}

abtben@yahoo.com (B. T. Anang), amikj26@yahoo.com (J. Amikuzuno)

\section{To cite this article:}

Benjamin Tetteh Anang, Joseph Amikuzuno. Factors Influencing Pesticide Use in Smallholder Rice Production in Northern Ghana. Agriculture, Forestry and Fisheries. Vol. 4, No. 2, 2015, pp. 77-82. doi: 10.11648/j.aff.20150402.19

\begin{abstract}
Rice production is an important economic activity among smallholder farmers in northern Ghana serving as source of income and household food security. The production of rice is often associated with the use of pesticides to control harmful pests of rice, a practice which also poses environmental and human health risks. The study sought to investigate the factors which influence smallholder rice farmers' use of pesticides in rice farming in northern Ghana. Rice farmers were selected from three irrigation schemes in northern Ghana, namely the Botanga, Tono and Vea Irrigation Schemes. A multi-stage stratified random sampling technique was used to identify 300 rice farmers who were interviewed with a semi-structured questionnaire. The data was analyzed both descriptively and inferentially. A probit model was used to study the determinants of pesticide use. The study showed that farm size, farm income, mechanization, extension contact, distance to source of pesticide and production system were the influencial factors in rice producers' choice to use pesticide in rice farming. The study recommends extension education to farmers on pesticide use in order to avoid misuse and the risks factors associated with improper application.
\end{abstract}

Keywords: Northern Ghana, Pesticide Use, Probit Model, Rice Production, Smallholder Farmers

\section{Introduction}

Pesticides are chemical substances containing a very diverse array of chemical structures. Pesticides can be classified under agrochemicals which are crop protection products or agents used to control plants or weeds, diseases, insects or animals that are undesirable or harmful to man, and/or also to promote the growth and development of crops. According to [1] and [2], the commonly used agrochemicals in Ghana are insecticides, herbicides, fungicides, fumigants, fertilizers and growth regulators. The complex nature of many pesticides does not make the classification of pesticides simple. A convenient classification of pesticides is based on the targeted pest. For example, insecticides target insects, herbicides target weeds, fungicides target fungi, nematicides target nematodes while rodenticides target rodents. There is a further subdivision of each class into smaller subclasses based on chemical structure. In terms of total use, herbicidesaccount for the largest proportion of pesticide use.

Pesticides are widely used in agricultural production to protect crops and animals from pest such as insects, mites, birds, ticks, rodents, nematodes, weeds, fungi, and other organisms that cause losses. They are also used to maintain product quality. Some pesticides are prepared locally by farmers and these are called natural pesticides such as neem extract and wood ash. Other pesticides are manufactured in industries through advanced procedures and are known as synthetic or artificial pesticides. This study focused on the use of synthetic or artificial pesticides by smallholder rice farmers.

It has been shown that the pesticides used in agricultural, commercial, home and garden applications are associated with great health risk including cancer [3]. According to ]4], acute poisoning with pesticides is a global public health problem accounting for as many as 300,000 deaths worldwide every year.

As noted by [5], low yields and productivity are compounded in the long-run by production shocks arising from environmental stresses such as drought, pests, and diseases. Despite chemical control measures to increase agricultural production, $20-40 \%$ of potential food production is still lost every year to pests and diseases [6]. 
The use of pesticides is thus important to farmers to control pests and diseases. From an agricultural industry perspective, pesticides are an important component of economic and effective pest control and their continued use is considered essential [7]. It therefore comes as little surprise that pesticide use has increased over time in Ghana and is particularly elevated in the production of high-value cash crops and vegetables [8]. Chemical pesticides are also used improperly or in dangerous combinations as noted by [9]. The promotion of safe use of pesticides on vegetables has been put on the agenda of Ghana's Food and Agriculture Sector Development Policy in recognition of the misuse of chemical pesticides in the country [10].

\section{Methodology}

The following section presents the methodology employed in gathering and analyzing the data for the study together with the analytical and empirical frameworks.

\subsection{Analytical Framework and Empirical Model}

Probit analysis permits the estimation of dichotomous dependent variables within the regression framework. Many response variables are binary by nature, requiring either a yes or no (or 1/0) response. Ordinary least squares (OLS) regression is inadequate when we have dependent variables that are discrete [11],[12]. Probit and logit analyses become more convenient when dealing with such situations.

The probit model constrains the estimated probabilities to lie between 0 and 1, relaxing the constraint that the effect of the independent variable is constant across different predicted values of the dependent variable. The probit model makes the assumption that while we only observe the values of 0 and 1 for the dependent variable $\mathrm{Y}$, there is a latent, unobserved continuous variable $Y^{*}$ that determines the value of $Y[13]$. This study uses the probit model to determine the factors influencing pesticide use in smallholder rice production at three irrigation schemes in northern Ghana.

Suppose the response variable $\mathrm{Y}$ is binary; with only two possible outcomes denoted as 1 and 0 . Consider also a vector of regressors $\mathrm{X}$, which are assumed to influence $\mathrm{Y}$. Specifically we assume that the model takes the form:

$$
\operatorname{Pr}(Y=1 \mid X)=\Phi\left(X^{\prime} \beta\right)
$$

Where Pr stands for probability and $\Phi$ is the Cumulative Distribution Function (CDF) of the standard normal distribution. The parameters $(\beta)$ are estimated by the method of maximum likelihood.The Probit model for the study can be written as:

$$
Y=F\left(\alpha+\beta x_{i}\right)=F\left(z_{i}\right)
$$

Where $Y=$ the discrete choice variable, that is, pesticide use; $F=$ the cumulative probability distribution function; $\beta=$ a vector of parameters; $x=$ the vector of explanatory variables, and $z=$ the Z-score of $\beta x$ for the area under the normal curve.

It is assumed that $Y$ can be specified as follows:

$$
Y=\beta_{0}+\beta_{1} X_{1 i}+\beta_{2} X_{2 i}+\ldots . .+\beta_{11} X_{11 i}+V_{i}
$$

And that:

$$
Y=1_{i f Y^{*}>0} \text { and } Y=0_{\text {Otherwise }}
$$

Where $X_{1}, X_{2}, \ldots ., X_{11}$ represent vector of random variables, $\beta$ is a vector of unknown parameters, and $\mathrm{V}$ is a random disturbance term.

\subsection{The Empirical Model}

The probit model for the study was specified as follows:

$$
Y_{i}=\beta_{0}+\sum_{i=1}^{11} \beta_{i} X_{i}+v
$$

where $Y_{i}=$ pesticide use $(=1$ if the farmer used pesticide, 0 otherwise), $x_{1}=$ sex of farmer, $x_{2}=$ educational attainment, $x_{3}$ $=$ years of experience in rice production, $x_{4}=$ farm size; $x_{5}=$ farm income squared, $x_{6}=$ farm income squared; $x_{7}=$ mechanization using tractor; $x_{8}=$ number of extension contact; $x_{9}=$ distance to pesticide selling point; $x_{10}=$ production system (binary): 1 if farm is irrigated, 0 otherwise; $x_{11}=$ regional dummy (binary): 1 if in Northern Region, 0 otherwise. The $\beta$ s are unknown parameters to be estimated.

\subsection{Study Area}

The study was carried out in the three regions of Northern Ghana, namely the Upper East, Upper West and Northern Regions. The Northern and Upper East Regions were purposively selected for the study because of their irrigation potential for rice production. The three largest irrigation schemes notable for rice cultivation are located in these Regions. Ghana has a total land area of $238,540 \mathrm{~km}^{2}$ and has a warm humid climate. There are six ecological zones in Ghana namely the rain forest, the deciduous forest, the transitional zone, the Guinea Savannah, the Sudan Savannah, and the Coastal savannah. Rainfall distribution is bimodal for the forest, transitional and coastal zones resulting in two cropping seasons, the major and the minor seasons. On the other hand, the savannah zone which comprises the three Regions of northern Ghana has a mono-modal rainfall distribution which gives rise to only one cropping season. The rainy season permits a growing season of 150-160 days in the Upper East Region and 180-200 days in the Northern Region. Mean total annual rainfall ranges from 1,000 $\mathrm{mm}$ in the Upper East Region to 1,200 in the south-eastern part of the Northern Region. Northern Ghana has a total area of $98,000 \mathrm{~km}^{2}$, of which $16,000 \mathrm{~km}^{2}$ is intensely farmed and about $8,000 \mathrm{~km}^{2}$ is less intensely farmed [14].

\subsection{Sampling and Data Collection}

The data was obtained from a farm household survey conducted during the 2013/2014 farming season. A total of 
300 rice farmers were selected from fifteen (15) communities and interviewed using semi-structured questionnaire which was pre-tested. A stratified multi-stage sampling technique was used. The three largest irrigation schemes in northern Ghana were purposively sampled. These are the Tono Irrigation Scheme in the Kassena-Nankana District of the Upper East Region, the Vea Irrigation Scheme in the Bolgatanga District also in the Upper East Region, and the Botanga Irrigation Scheme in the Tolon-Kumbungu District of the Northern Region. Five communities were randomly selected from each catchment area of the three irrigation schemes to form the target farming communities in which the questionnaire were administered. Rice farmers in each community were stratified into irrigators and non-irrigators with equal samples of irrigators and non-irrigators being randomly selected. Pesticide use in rice cultivated was solicited from farmers as well as other household and production data.

The data was subjected to both descriptive and inferential statistical analysis. The descriptive statistics included measures such as frequencies, percentages, means, and standard deviations. The probit model was used to determine the factors influencing pesticide use in rice production by smallholder farmers in northern Ghana.

\section{Results and Discussions}

This section provides a description of the data used for the study followed by a presentation of the results of the probit model which estimates the role of the factors influencing pesticide use bysmallholder rice farmers in Northern Ghana.

\subsection{Description of Variables Used in the Study}

Table 1 shows the explanatory variables used in the study and their description. The hypothesized signs of the variables are also presented.

Table 1. Description of the explanatory variables used in the study.

\begin{tabular}{lll}
\hline Variable Description & Measurement & Expected sign \\
\hline Sex of respondent & Dummy: 1 for male; 0 for otherwise \\
Educational attainment in years & Continuous \\
Experience in rice production (years) & Continuous \\
Farm size (in acres) & Continuous \\
Farm income (Ghana Cedi) & Continuous \\
Mechanization indicated by tractor use & Dummy: 1 for tractor use; 0 otherwise \\
Number of extension contacts made & Continuous \\
Distance to pesticide selling point & Continuous \\
Production system (access to irrigation) & Dummy: 1 if farm isirrigated; 0 for otherwise \\
Regional dummy & Dummy: 1 if in Northern Region; 0 for otherwise $+/-$ \\
\hline
\end{tabular}

The effect of gender, farming experience, mechanization use and access to irrigation on the choice to use pesticides are hypothesized to be indeterminate. This means that the effect can be either positive or negative. However, educational attainment, number of extension contacts and distance to pesticide selling point are hypothesized to have a negative effect on pesticide use. For example, an increase in the distance to the pesticide selling point is associated with additional cost of production to the farmer which is likely to reduce pesticide adoption. Similarly, farmers who receive extension contacts as well as farmers who are educated are expected to acquire knowledge of various methods of controlling pests and diseases and may be less disposed to use pesticides in rice production. An increase in both farm size and farm income is hypothesized to increase pesticide use because as farm size increases, pest control becomes more difficult while an increase in income makes pesticide acquisition more affordable to the farmer.

Table 2 gives the descriptive statistics of the relevant variables used in the model.

Table 2. Descriptive statistics of relevant variables.

\begin{tabular}{|c|c|c|c|}
\hline Variable & $\begin{array}{l}\text { Pesticide Users } \\
\mathrm{N}=\mathbf{2 1 8}\end{array}$ & Non-users $\mathbf{N}=82$ & $\begin{array}{l}\text { Overall } \\
\mathrm{N}=\mathbf{3 0 0}\end{array}$ \\
\hline Farm size (in acres) & 2.39 & 2.02 & 2.29 \\
\hline Experience in rice production (years) & 15.2 & 15.9 & 15.4 \\
\hline Farm income (Ghana Cedis) & 1879 & 1696 & 1829 \\
\hline Mechanization (\%) & 72.5 & 45.1 & 65.0 \\
\hline Number of extension contacts made & 2.58 & 5.23 & 3.31 \\
\hline Production system (irrigation use) (\%) & 48.0 & 55.0 & 50.0 \\
\hline Northern Region (\%) & 14.6 & 40.4 & 33.3 \\
\hline Upper East Region (\%) & 85.4 & 59.6 & 66.7 \\
\hline Male $(\%)$ & 82.6 & 67.1 & 78.3 \\
\hline Female $(\%)$ & 17.4 & 32.9 & 21.7 \\
\hline
\end{tabular}


Table 3. Probit regression results.

\begin{tabular}{llll}
\hline Variables & Coefficient & $\mathbf{P}>\mathbf{z}$ & Marginal Effect \\
\hline Sex & 0.283 & 0.202 & 0.090 \\
Education & $(0.222)$ & & -0.006 \\
& -0.019 & 0.262 & -0.002 \\
Experience & $(0.017)$ & 0.413 & 0.048 \\
Farm size & -0.007 & & $0.040^{* *}$ \\
Farm income & $(0.008)$ & & 0.215 \\
Farm income squared & 0.159 & $0.024^{* *}$ & -0.080 \\
Mechanization & $(0.077)$ & $0.001^{* * *}$ & 0.234 \\
Extension contact & 0.716 & & -0.015 \\
Distance & $-0.268)$ & $0.000^{* * *}$ & \\
Production system & $(0.084)$ & $0.005^{* * *}$ & -0.025 \\
Region & 0.734 & $0.189)$ & -0.140 \\
Constant & -0.049 & $0.000^{* * *}$ & 0.051 \\
\hline
\end{tabular}

${ }^{* * *},{ }^{* *}$, and ${ }^{*}$ indicate statistical significance at the 1,5 and 10 percent level, respectively. $\mathrm{R} 2=0.20$, Percentage correctly predicted $=77.0$. Figures in parentheses are standard errors.

Pesticide users did not differ much from non-users in terms of farm size and years of farming experience. Pesticide users had slightly higher farm income compared to non-users. Hence an increase in income is likely to positively influence pesticide use. Pesticide users also had less extension contact and shorter distance to pesticide selling point compared to the non-users. Thus nearness to the pesticide selling point enhances the use of pesticides. Irrigation access was found to be lower for pesticide users compared to the non-users while mechanization (tractor use) was higher among pesticide users compare to the non-users. Thus irrigation access is likely to have a negative effect on pesticide use while mechanization is likely to have a positive effect. In addition, majority of pesticide users were found in the Upper East Region while men exceeded women in the use of pesticide in rice cultivation. Pesticide use is therefore likely to be positively related to being a male farmer as well as being located in the Upper East Region.

\subsection{Factors Influencing Pesticide Useby Smallholder Rice Farmers}

Table 3 presents the result of the probit analysis and the marginal effects of the probit regression.

Farm size was positively related to pesticide use and was significant at the 5 percent level. Thus an increase in farm size increases the probability of adoption of pesticide in rice production in the study area. The marginal effect of 0.048 indicates that a unit increase in farm size increases the probability of pesticide use by 4.8 percent. The result is at variance with [15] who found a negative correlation betweeen farm size and pesticide use. The study is however consistent with [16] who found a positive relation between agrochemical use and farm size. From our study, we deduce that as farm size increases, farmers are unable to effectively control pests and diseases manually without resorting to pesticide use. Hence an increase in farm size increases the likelihood of pesticide use in rice production by farmers.

Farm income also exhibited a positive and significant relationship with pesticide use which is consistent with [17] who found income of farmers to be positively related to the level of pesticide use in Nigeria. This shows that an increase in farm income increases the predicted probability of pesticide use in rice farming by 0.22 , as indicated by the marginal effect. The squared value of farm income was significant but negative, indicating that as farm income increases beyond a critical point, the probability of pesticide use decreases by 0.08 . Thus an initial increase in farm income increases pesticide use but futher increase in income leads to a decrease in the use of the chemical input. The result is to be expected because as farm income increases, farmers are expected to be able to afford to purchase the quantity of pesticides they need. However, with further increase in income, the farmer is less likely to continue to increase pesticide use because beyond a certain point, pesticide use is no longer beneficial. Diminishing marginal returns sets in with the application of the chemical and less amount is used.

Mechanization or tractor use had a positive and significant relationship with pesticide use. Hence farmers who used mechanization were more likely to use pesticide in rice farming compared to those who did not use mechanization. The probability of pesticide use by farmers who use mechanized farm implements was 0.23 higher than those 
who did not use mechanization.

Contact with extension agents exhibited a significantly negative relationship with pesticide use, implying that pesticide use decreases with contact with extension agents. Hence an additional increase in extension contact decreases the probability of pesticide use in rice farming by 0.02 . It is generally expected that in order to reduce yield losses due to pests and diseases farmers will use more pesticides, all things being equal. The study however shows that extension contacts tend to reduce the use of pesticide in rice farming. One possible reason is the introduction of integrated pest management (IPM) to farmers to reduce pesticide use particularly in rice farming. For example, IPM Farmer Field Schools which started in Indonesia in 1989 was designed to reduce pesticied use in rice production [18]. The IPM farmer field schools have been replicated in over 30 countries worldwide. In Ghana, similar activities by the Ministry of Food and Agriculture through extension education with farmers have been ongoing and this could account for the reduction in pesticide use in rice farming by farmers with more extension contacts.

Distance to the source of pesticide had a significantly negative relationship with pesticide use, indicating that pesticide use decreases with distance and hence the transaction cost needed to travel to acquire the input. An increase in the distance to the pesticide selling point from the farm decreases the probability of pesticide use by 0.03 . The result is consistent with a priori expectation since an increase in transaction cost due to long travel distance is expected to decrease input use, all things being equal.

Finally, the production system used by the farmers exhibited a negatively significant relationship with pesticide use. This implies that irrigation users were less likely to use pesticide in rice production compared to non-irrigation users. The probability of pesticide use by users of irrigators was 0.14 lower than those who did not use irrigation.

\section{Conclusion}

Pesticide use in rice production is influenced by certain household characteristics such as farm size, farm income, the adoption of farm mechanization, extension contact, distance to the source of pesticide and whether the farmer uses irrigation or not. In addition, rain-fed farmers were more disposed to use pesticides in rice cultivation compared to irrigation users. However regional variation, sex, education and farming experience were less likely to influence pesticide use in the study area.

The study recommends the intensification of extension education to farmers and particularly, the IPM Farmer Field School system since it has been found to influence pesticide use by farmers. As noted by [18], production losses due to pests and diseases compel farmer to excessively use pesticides. Thus extension service to farmers is one major channel to educate farmers on pesticide use to avoid misuse and the risks factors associated with improper application.

\section{Acknowledgement}

The authors would like to thank Wienco Ghana Ltd and Wienco Chair Research Committee of the Faculty of Agriculture of the University for Development Studies for providing funding for the research.

\section{References}

[1] Ntow, W. J., 2004. Organochlorine Pesticides in Water, Sediments, Crops and Human Fluids in a Farming Community in Ghana. Journal of Archives of Environmental Contamination and Toxicology. 40(4): 557-563.

[2] Pan African Regulation (PAR), 2000. Pan Africa Regulation of Dangerous Pesticides in Ghana. Pan African Monitoring and Briefing Series No. 5, Dakar, Senegal, 16Pp.

[3] Alavanja M. C. R., Ross M. K., and Bonner M. R,.2013. Increased Cancer Burden Among Pesticide Applicators and Others Due to Pesticide Exposure. CA Cancer J Clin 2013 (63):120-142. doi:10.3322/caac.21170. Available online at cacancerjournal.com.

[4] Goel A. and Aggarwal P., 2007. Pesticide poisoning. The National Medical Journal of India, Vol. 20, No. 4. Review Article 182. July/August 2007.

[5] Horna D, Smale M., Al-Hassan R., Falck-Zepeda J., and Timpo S. E.,2008. Insecticide Use on Vegetables in Ghana: Would GM Seed Benefit Farmers? IFPRI Discussion Paper 00785, August 2008.

[6] Obeng-Ofori, D., 1998. Post Harvest Science. Crop Science Department. University of Ghana, Legon, October, 1998. 71 Pp.

[7] Kent, J., 1991. Education and Training in Farm Chemical Management. Proceedings of Conference on Agriculture, Education and Information Transfer. Murrumbidge College of Agriculture, 1991.

[8] Gerken, A., Suglo, J.-V. and Braun, M., 2001. Crop Protection Policy in Ghana. Pokuase-Accra, Ghana: Integrated Crop Protection Project, PPRSD/GTZ.

[9] Obeng-Ofori, D., Owousu, E. O. and Kaiwa E. T., 2002. Variation in the level of carboxylesterase activity as an indicator of insecticide resistance in populations of the diamondback moth Plutella xylostella (L.) attacking cabbage in Ghana. Journal of the Ghana Science Association 4 (2): 52-62.

[10] Ministry of Food and Agriculture, 2002. Food and agriculture sector development policy. Accra: Government of Ghana.

[11] Collett D., 1991. Modelling Binary Data, London: Chapman and Hall.

[12] Agresti A., 1990. Categorical Data Analysis, New York: John Wiley \& Sons.

[13] Sebopetji TO, Belete A., 2009.An Application of Probit Analysis to Factors Affecting Small-Scale Farmers' Decision to take Credit: a Case Study of Greater Letabo Local Municipality in South Africa. Afri. J. Agric. Res. 4(8):718-723.

[14] Al-hassan, S., 2008. Technical Efficiency of Rice Farmers in Northern Ghana. AERC Research Paper 178, African Economic Research Consortium, Nairobi. April 2008. 
[15] Yasin G, Aslam M, Parvez I. and Naz S., 2003. Socioeconomic Correlates of Pesticide Usage: The Case of Citrus Farmers. Journal of Research (Science), Bahauddin Zakariya University, Multan, Pakistan 14 (1):43-48, June 2003.

[16] Alabi O. O., Lawal A. F., Coker A. A. and Awoyinka Y. A., 2014. Probit Model Analysis of Smallholder's Farmers Decision to Use Agrochemical Inputs in Gwagwalada and Kuje Area Councils of Federal Capital Territory, Abuja, Nigeria. International Journal of Food and Agricultural Economics 2(1):85-93.
[17] Idris A, Rasaki K., Folake T., and Hakeem B., 2013. Analysis of Pesticide Use in Cocoa Production in Obafemi Owode Local Government Area of Ogun State, Nigeria. Journal of Biology, Agriculture and Healthcare 3(6):1-9.

[18] Rahman, A. M. A. and Hamid, M E., 2013. Impact of FFS on Farmer's Adoption of IPM Options for Onion: A Case Study from Gezira State, Sudan. World Journal of Agricultural Sciences 9 (1): 38-44. DOI: 10.5829/idosi.wjas.2013.9.1.1720. 